\title{
Expiratory valves used for home devices: experimental and clinical comparison
}

\author{
F. Lofaso*, P. Aslanian*, J.C. Richard*, D. Isabey*, T. Hang**, E. Corriger**, \\ A. Harf*, L. Brochard*
}

Expiratory valves used for home devices: experimental and clinical comparison. F. Lofaso, P. Aslanian, J.C. Richard, D. Isabey, T. Hang, E. Corriger, A. Harf, L. Brochard. OERS Journals Ltd 1998.

ABSTRACT: A bench study followed by a clinical trial were performed to evaluate the mechanical characteristics of five (commercially available) expiratory valves used for home ventilators, as well as the potential clinical impact of differences between these valves.

In the in vitro study, expiratory valve resistance was evaluated under unvarying conditions, whereas dynamic behaviour was evaluated by calculating the imposed expiratory work of breathing during a simulated breath generated by a lung model. Differences in resistance and imposed expiratory work of up to twofold and $150 \%$, respectively, were found across valves. We then conducted a randomized crossover clinical study to compare the effects of the least resistive (Bennett) and most resistive expiratory valves (Peters) in 10 intubated patients receiving pressure support ventilation.

There were no significant differences regarding blood gases or respiratory parameters except for the oesophageal pressure-time product (PTPoes), which was significantly increased by the Peters valve $\left(236 \pm 113 \mathrm{cmH}_{2} \mathrm{O} \cdot \mathrm{s}^{\cdot \mathrm{min}^{-1}}\right.$ versus $194 \pm 90$ $\left.\mathrm{cmH}_{2} \mathrm{O} \cdot \mathrm{s} \cdot \mathrm{min}^{-1}\right)$. An analysis of individual responses found that the Peters valve induced substantial increases in intrinsic positive end-expiratory pressure (PEEP), PTPoes, and expiratory activity in those patients with the greatest ventilatory demand.

In conclusion, differences between home expiratory valve resistances may have a clinically relevant impact on the respiratory effort of patients with a high ventilatory demand.

Eur Respir J 1998; 11: 1382-1388.

Over the last $10 \mathrm{yrs}$ the number of patients receiving assisted ventilation at home has increased markedly [1]. As a result, there has been a resurgence of interest in the technical aspects of ventilators used to provide ventilatory support at home [2-5]. Perhaps because exhalation is usually passive, few studies have focused on the flow-impeding characteristics of external circuit components [6-8]. The expiratory valve occludes the expiratory limb of the respiratory circuit during inspiration and opens at the beginning of expiration. An ideal expiratory valve should completely obstruct air outflow during inspiration, but should offer little or no resistance to expiration in order to avoid dynamic hyperinflation or expiratory muscle recruitment.

The majority of home ventilator devices can be used with a range of expiratory valves, but criteria for rational selection of an expiratory valve are lacking since no formal evaluations of the performances of commercially available expiratory valves are available.

In the first part of this study, we examined the performance characteristics of five commercially available diaphragm or balloon expiratory valves (table 1). Data were gathered during a bench evaluation of the resistive properties of exhalation valves under quasi-static and dynamic conditions.

\begin{abstract}
*Institut National de la Santé et de la Recherche Médicale INSERM U 296, Services de Physiologie-Explorations Fonctionnelles et de Réanimation Médicale, Hôpital Henri Mondor, Créteil, France. **Association d'Entraide des Polios et Handicapés (ADEP), Puteaux, France.
\end{abstract}

Correspondence: F. Lofaso

Service de Physiologie-Explorations Fonctionnelles

Hôpital Henri Mondor

94010 Creteil

France

Fax: 33149812667

Keywords: Expiratory activity

expiratory valves

inspiratory activity

intrinsic positive end-expiratory pressure

Received: July 71997

Accepted after revision November 281997

This study was supported in part by a grant from the Association d'Entraide des Polios et Handicapés (ADEP)
The purpose of the second part of the study was to evaluate the clinical relevance of the differences found between two expiratory valves during the first part of the study. We investigated critically ill patients undergoing weaning from mechanical ventilation. Each patient was ventilated with the same home pressure support device (O'Nyx; Pierre Médical, Puritan Bennett, France) during the comparison. The effects of the two valves were evaluated based on expiratory activity as assessed by gastric pressure tracing, intrinsic positive end-expiratory pressure (PEEPi), oesophageal pressure-time product (PTPoes), and respiratory pattern.

Table 1. - List of the five expiratory valves tested

\begin{tabular}{lcc}
\hline Brand & Model No. & Type of valve \\
\hline Peters (Bobigny, France) & $40-314160$ & Diaphragm \\
Bennett (San Diego, Mexico) & T.T 11 372-00 & Balloon \\
Pierre Médical (Verrières les & EX0008 & Diaphragm \\
Buisson, France) & 003283 & Balloon \\
Sims (Myers, USA) & KY 097600 & Balloon \\
Taema (Antony, France) & \\
\hline
\end{tabular}

These values were all primarily designed for home use. 


\section{Methods}

\section{Experimental in vitro studies}

Valves tested. Two diaphragm and three balloon valves were investigated (table 1). The function of all of these valves is based on similar principles. In most home ventilators, gas is diverted from the inspiratory limb internal to the ventilator or from a secondary gas control module to the diaphragm or balloon of the exhalation valve, which inflates, thus occluding the exhalation port during the inspiratory phase. Since these exhalation valve charging lines are internal to the ventilator, the pressure affecting the exhalation valve is always higher than the pressure in the airway. This pressure difference is thought to minimize the risk of leakage through the exhalation valve.

Quasi-static study. Experimental design A (fig. 1A) was used to measure the pressure-flow relationship through the expiratory valve. Compressed air was used to deliver a predetermined steady airflow, measured by a pneumotachograph (Fleisch\#2; Gould Electronique, Longjumeau, France) coupled to a second differential transducer (Validyne DP $45 \pm 2 \mathrm{cmH}_{2} \mathrm{O}$; Northridge, CA, USA). Pressure drop was measured using a differential pressure transducer (Validyne DP $45 \pm 2 \mathrm{cmH}_{2} \mathrm{O}$; Northridge, CA, USA) with one port opened to the atmosphere and the other port measuring the lateral pressure upstream from the valve. The flow values tested were in the range $0.25-1.5 \mathrm{~L} \cdot \mathrm{s}^{-1}$.

Dynamic study. In experimental design B (fig. 1B), the expiratory valves were evaluated during simulated ventilation with pressure support ventilation. The home pressure device used for this study was the O'Nyx (Pierre Médical, Puritan Bennett. France), whose performances have been found to be similar to intensive care unit devices [5]. Inspiratory pressure level was set at $10 \mathrm{cmH}_{2} \mathrm{O}$, positive end-expiratory pressure (PEEP) at its lowest level (i.e. $<0.5 \mathrm{cmH}_{2} \mathrm{O}$ ), and the rate of pressure support insufflation at the highest possible value. Pressure support was stopped during the decelerating phase at $25 \%$ of the peak inspiratory flow and exhalation was totally passive.

To simulate repeated inspiratory efforts, the pressure support ventilator (PSV) device was connected to a lung model (fig. 1B). The lung model was a two-chamber Michigan test lung. One chamber was connected to and powered by a CPU ventilator (Ohmeda, Maurepas, France) (driving chamber), whereas the other chamber (PSV pressurized chamber) was connected to the PSV ventilator under test. The CPU ventilator was set to ensure a respiratory frequency of 15 cycles $\cdot \mathrm{min}^{-1}$, an inspiratory time of $1.15 \mathrm{~s}$ and a constant inspiratory flow of $30 \mathrm{~L} \cdot \mathrm{min}^{-1}$. The two chambers were physically connected by a small metal component that allowed the driving chamber to lift the PSV pressurized chamber, mimicking the patient's contribution to inspiration. Thus, generation of positive pressure in the driving chamber by the CPU ventilator lowered the pressure in the PSV pressurized chamber to subatmospheric levels, just as negative alveolar pressures are produced in vivo when the inspiratory muscles contract. This effect was detected by the triggering system of the PSVs under test. Because the metal component was not secured to the PSV pressurized chamber, the latter, once effectively pressurized, could rise above the driving chamber. The compliance of both chambers was set at $82 \mathrm{~mL} \cdot \mathrm{cm}$ $\mathrm{H}_{2} \mathrm{O}^{-1}$. PEEP was applied to the driving chamber at a level that ensured synchrony of motion of the two chambers at

A)
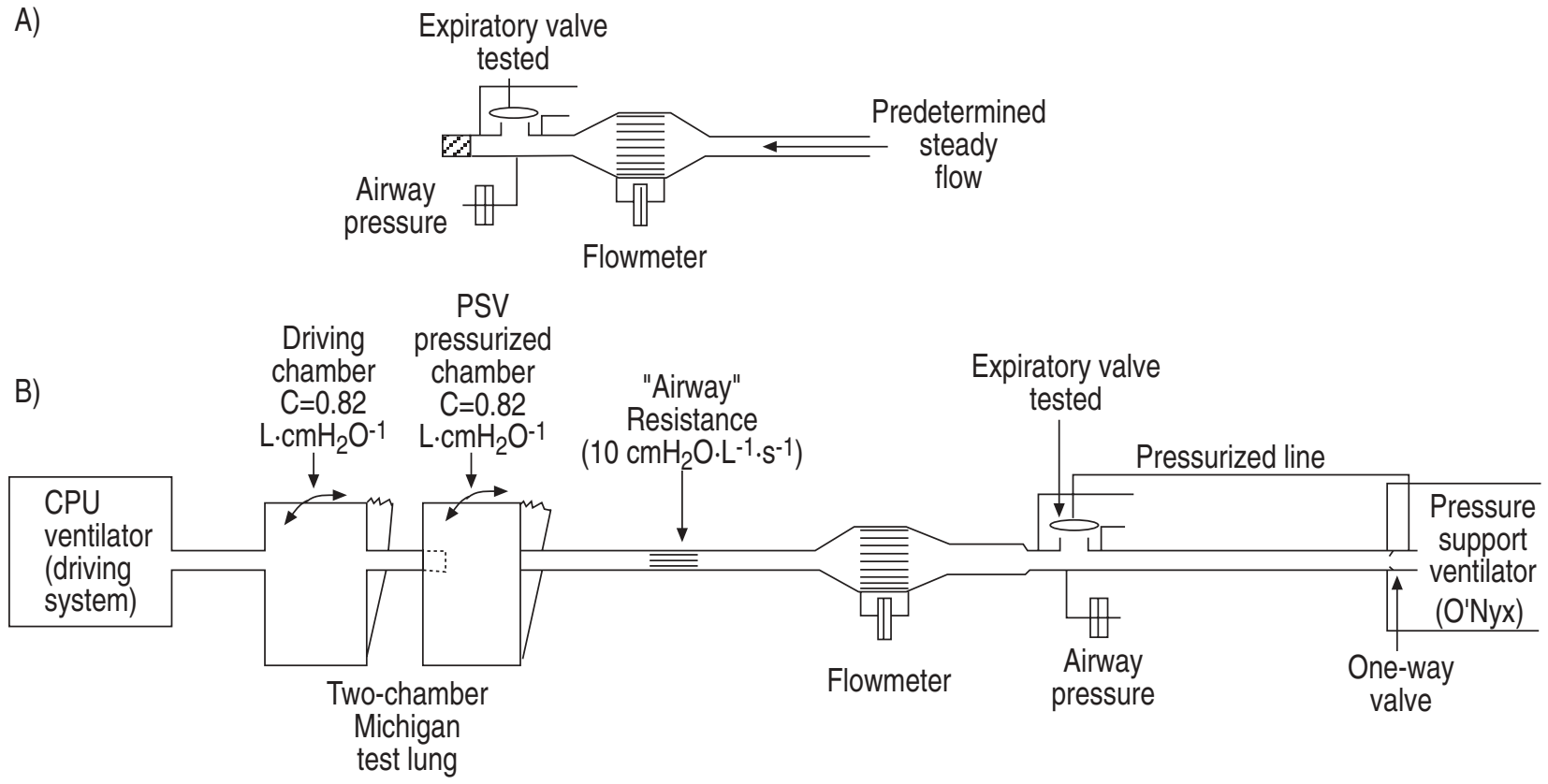

Fig. 1. - Experimental set up: A) in the quasi-static condition; and B) in the dynamic condition. In the quasi-static condition, a variable flow was adjusted and pressure and flow were measured at the extremity of the expiratory valve circuit. In the dynamic condition, the circuit of the expiratory valve was connected to a two-chamber Michigan test lung. One chamber (driving chamber) of the test lung was attached to and powered by a ventilator; the other chamber was connected to a pressure-support ventilator (PSV pressurized chamber). The two chambers were physically connected by a small metal component that allowed the driving chamber to lift the PSV pressurized. Because the metal component was not secured to the PSV pressurized chamber, the latter could expand freely as dictated by the pressure support level and could deflate freely during expiration. Pressure and flow were measured at the extremity of the ventilator circuit. CPU ventilator: Ohmeda, Mauvepas, France. 
onset of inspiration. A resistance of $10 \mathrm{cmH}_{2} \mathrm{O}$ at $1 \mathrm{~L} \cdot \mathrm{s}^{-1}$ was used to connect the device being studied to the lung model. Under these conditions, tidal volume in the pressurized chamber was $770 \mathrm{~mL}$.

To measure the expiratory work imposed by the expiratory valve $(W \mathrm{EV})$, a Fleisch\#2 pneumotachograph was inserted between the lung model and the circuit of the tested device, and airway pressure $(P$ aw $)$ was measured at the distal end of the circuit using a differential pressure transducer (Validyne MP45 $\pm 70 \mathrm{cmH}_{2} \mathrm{O}$, Northridge, CA). Signals were digitized at $128 \mathrm{~Hz}$ and sampled using an analogic/numeric system (MP100; Biopac Systems, Goleta, USA). WEV was calculated based on the area between the recorded volume-pressure curve during expiration and the same reference pressure corresponding to the endexpiratory pressure (fig. 2):

$$
W \mathrm{EV}=1 / 2 \begin{aligned}
& \text { end } t \mathrm{E} \quad P \mathrm{aw} \cdot V^{\prime} \mathrm{dt} \\
& \text { end } t \mathrm{I}
\end{aligned}
$$

where $V^{\prime}$ is the flow given by the pneumotachograph, and $t \mathrm{I}$ and $t \mathrm{E}$ are the inspiratory and expiratory times, respectively.

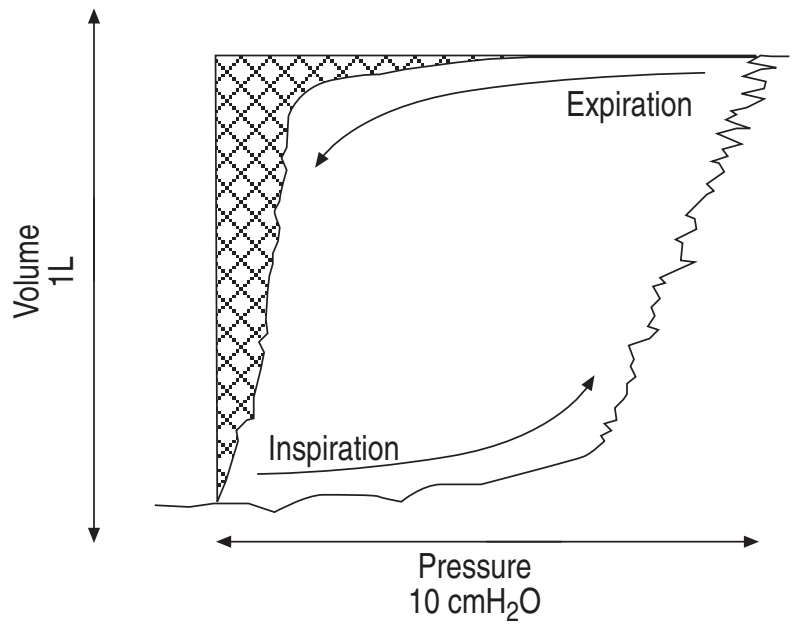

Fig. 2. - Volume-pressure curve obtained in the dynamic condition (fig. 1b). : expiratory work

Table 2. - Characteristics of the 10 patients studied

\begin{tabular}{|c|c|c|c|c|c|c|}
\hline $\begin{array}{l}\text { Patient } \\
\text { No. }\end{array}$ & $\begin{array}{l}\text { Sex } \\
\text { M/F }\end{array}$ & $\begin{array}{c}\text { Age } \\
\text { yrs }\end{array}$ & $\begin{array}{c}\text { Duration of ventilation } \\
\text { days }\end{array}$ & $\begin{array}{l}\text { IPS level } \\
\mathrm{cmH}_{2} \mathrm{O}\end{array}$ & $\begin{array}{l}\text { Diagnosis at } \\
\text { admission }\end{array}$ & Outcome \\
\hline 1 & $\mathrm{~F}$ & 36 & 8 & 15 & Myasthenia & Survived \\
\hline 2 & $\mathrm{M}$ & 64 & 15 & 22 & $\begin{array}{c}\text { COPD } \\
\text { Pneumonia }\end{array}$ & $\begin{array}{c}\text { Survived } \\
\text { Tracheotomy }\end{array}$ \\
\hline 3 & M & 59 & 41 & 20 & $\begin{array}{l}\text { Pneumonia } \\
\text { Pancreatitis }\end{array}$ & Survived \\
\hline 4 & M & 53 & 2 & 20 & Pneumonia & Survived \\
\hline 5 & $\mathrm{~F}$ & 72 & 11 & 14 & $\begin{array}{l}\text { Lymphoma } \\
\text { Pneumonia }\end{array}$ & Survived \\
\hline 6 & M & 69 & 2 & 15 & Abdominal surgery & Survived \\
\hline 7 & M & 60 & 11 & 12 & $\begin{array}{c}\text { COPD } \\
\text { Brain infarction }\end{array}$ & $\begin{array}{c}\text { Survived } \\
\text { Tracheotomy }\end{array}$ \\
\hline 8 & $\mathrm{~F}$ & 47 & 10 & 20 & $\begin{array}{l}\text { Leukaemia } \\
\text { Pneumonia }\end{array}$ & Survived \\
\hline 9 & M & 52 & 13 & 12 & Liver transplant & Survived \\
\hline 10 & $\mathrm{M}$ & 63 & 10 & 20 & $\begin{array}{c}\text { COPD } \\
\text { Pneumonia }\end{array}$ & Survived \\
\hline
\end{tabular}

M: male; F: female; IPS: inspiratory pressure support; COPD: chronic obstructive pulmonary disease.
Statistics. Means and standard deviations were determined from a total of 15 valves for each valve model. Comparisons were made using paired Wilcoxon's tests. The level of significance was set at $5 \%$.

\section{Clinical study}

Valves tested. Two valves were tested: 1) the valve that was least resistive at 0.5 and $1 \mathrm{~L} \cdot \mathrm{s}^{-1}$ in the quasi-static study and generated the least expiratory work of breathing in the dynamic study (Ref TT 11 372-00; Bennett, San Diego, Mexico); and 2) the valve that was most resistive at 0.5 and $1 \mathrm{~L} \cdot \mathrm{s}^{-1}$ in the quasi-static study and generated the most expiratory work of breathing in the dynamic study (Ref 40-314160, Peters, Bobigny, France).

Patients. This study was approved by the Research Ethics Committee of our institution. All patients gave informed consent to participation in the study. Ten patients aged 3672 yrs were included. Their main clinical and respiratory features are listed in table 2. At the time of the study, all 10 patients were intubated or tracheotomized, and none could breathe spontaneously for more than $15 \mathrm{~min}$. Despite differences in the causes of respiratory failure, all patients satisfied the following criteria: 1) respiratory frequency ranging $15-35$ breaths. $\mathrm{min}^{-1}$ without PEEP and with an inspiratory pressure support (IPS) level under 20 $\left.\mathrm{cmH}_{2} \mathrm{O} ; 2\right)$ arterial oxygen tension $\left(\mathrm{Pa}_{2} \mathrm{O}_{2}\right)$ above $9.3 \mathrm{kPa}$ $(70 \mathrm{mmHg})$ with an inspired oxygen fraction $\left(\mathrm{F}_{\mathrm{I}}, \mathrm{O}_{2}\right)$ under $50 \%$; and 3 ) haemodynamic stability (without vasopressive drugs) and apyrexia.

Methods. An arterial line was inserted before measurements were started, to allow repeated arterial blood gas analysis. Blood gases were measured using an ABL 30 analyser (Radiometer, Copenhagen, Denmark).

Flows were measured using a Fleisch \#2 pneumotachograph connected to a differential pressure transducer (Validyne MP $45 \pm 5 \mathrm{cmH}_{2} \mathrm{O}$, Northridge, CA, USA). The flow signal was integrated to yield volume. Respiratory frequency and minute ventilation were calculated from the flow signal. $P$ aw was measured at the proximal end of the 
endotracheal tube using a differential pressure transducer (Validyne MP $45 \pm 70 \mathrm{cmH}_{2} \mathrm{O}$, Northridge, CA, USA). Gastric pressure $(P$ ga $)$ and oesophageal pressure $\left(P_{\text {oes }}\right)$ were measured using a probe with two piezo-electric sensors inserted through a nostril and advanced until the distal sensor was in the stomach and the proximal one was in the lower third of oesophagus (probe and amplifier Gaeltec S7B/2; Gaeltec Ltd. Dunvegan, Isle of Skye, UK). Correct positioning of the transducers was verified by observing $P$ ga fluctuations produced by applying gentle pressure to the subject's gastric area and by looking for a sharp increase in $P$ oes on the $P$ oes tracing when an oesophageal contraction was induced by asking the subject to drink water. In addition, the oesophageal balloon was positioned at the appropriate site after a pressure manoeuvre consisting of an occlusion test [9].

All signals were digitized at $128 \mathrm{~Hz}$ and sampled for subsequent analysis using an analogic/numeric acquisition system (MP100; Biopac System, Goleta, USA).

Expiratory muscle activity was evaluated as, described previously, from the changes in $P$ ga $[10,11]$. The direct mechanical effect of expiratory contraction of the abdominal muscles is an increase in $P$ ga during the expiratory phase of the breathing cycle. Therefore, we measured from the $P$ ga trace the decrease from the maximal end-expiratory level to the minimal value $(\Delta P \mathrm{ga})$.

The PTPoes was measured as the area enclosed within $P$ oes and the chest wall static recoil pressure $\left(P_{\text {stw }}\right)$-time curve over $t \mathrm{I}$, taking into account the PEEPi or, if $\Delta P_{\mathrm{ga}}$ was positive, the corrected PEEPi (corrected PEEPi = PEEPi - $\triangle P$ ga), as in previous studies $[11,12]$. PEEPi was defined as the $P$ oes decrease required to bring the expiratory flow abruptly to zero. The $P$ stw-time curve was extrapolated to the predicted value of chest wall compliance $(C$ stw), which theoretically contributes about $4 \%$ of the predicted value of vital capacity per centimetre of water. Thus, the slope of the $P$ stw-time relationship was:

\section{$(\Delta V \mathrm{~T} / C \mathrm{stw}) / \Delta t \mathrm{I}$}

where $\Delta V \mathrm{~T}$ is change in tidal volume and $\Delta t \mathrm{I}$ is change in inspiratory time.

PTPoes was multiplied by the respiratory frequency and expressed in $\mathrm{cmH}_{2} \mathrm{O} \cdot \mathrm{s} \cdot \mathrm{min}^{-1}$.

After elimination of abnormal cycles characterized by coughing or excessively small tidal volumes, the mean value for at least 10 breaths was determined for each parameter.

Protocol. Measurements with the two valves were performed in the morning of the same day, and lasted 3-4 h. All patients were studied in a semirecumbent position. Endotracheal suctioning was performed before each study period. Settings of pressure support ventilation were strictly identical with the two valves. The home pressure device used for this study was the O'Nyx (Pierre Médical, Puritan Bennett, France), whose performances have been found to be similar to those of intensive care unit devices. Because the O'Nyx device does not allow $F \mathrm{I}_{2} \mathrm{O}_{2}$ to be set, all patients were ventilated with room air, and an additional flow of oxygen was added to the ventilatory circuit if necessary and kept constant throughout the study.

The two valves were tested in random order. Patients were ventilated with each valve for $20 \mathrm{~min}$. Respiratory parameters were recorded during the last $5 \mathrm{~min}$ of each test period. Arterial samples for blood gas analysis were collected at the end of each period.

Statistics. Data are given as means \pm sD. Comparisons were made using paired Wilcoxon's tests. The level of significance was set at $5 \%$.

\section{Results}

\section{Experimental in vitro study}

The pressure-flow relationships obtained under quasistatic conditions with each expiratory valve are presented in table 3 . When flow was set at $0.5 \mathrm{~L} \cdot \mathrm{s}^{-1}$, pressure varied across valves, from $1.27-2.03 \mathrm{cmH}_{2} \mathrm{O}$. When flow was set at $1 \mathrm{~L} \cdot \mathrm{s}^{-1}$, greater than twofold pressure increases were seen across valves. Under dynamic conditions, expiratory work of breathing varied across valves, from $0.10 \mathrm{~J} \cdot$ cycle $^{-1}$ for the Bennett expiratory valve to $0.16 \mathrm{~J}$ cycle $^{-1}$ for the Peters expiratory valve. The dynamic expiratory pressurevolume relationship of these two valves are presented in figure 3 . Interestingly, we found a highly significant correlation between imposed expiratory work of breathing in the dynamic study and pressure values observed at $1 \mathrm{~L} \cdot \mathrm{s}^{-1}$ in the static study $(\mathrm{r}=0.92, \mathrm{p}<0.03)$ (fig. 4).

\section{Clinical study}

The main characteristics of the 10 patients are presented in table 2 . Nine patients required addition of oxygen (2-4 L. $\left.\mathrm{min}^{-1}\right)$. No significant differences were observed between the periods of ventilation with the Peters and the Bennett valves, in terms of arterial blood gases, respiratory parameters or PEEPi (table 4). PTPoes increased significantly with the Peters valve (table 4). An analysis of individual responses showed that the three patients (patients 3 , 7 and 10) with the highest minute ventilations (above 15 $\left.\mathrm{L} \cdot \min ^{-1}\right)$ and the shortest expiratory times exhibited substantial increases in both PEEPi and PTPoes with the Peters

Table 3. - Expiratory flow-pressure relationships through valves

\begin{tabular}{llllll}
\hline $\begin{array}{l}\text { Flow } \\
\mathrm{L} \cdot \mathrm{s}^{-1}\end{array}$ & Bennett & Peters & Taema & Sims & Pierre M. \\
\hline 0.25 & $0.88 \pm 0.99$ & $0.80 \pm 0.10$ & $0.87 \pm 0.27$ & $0.64 \pm 0.18^{*}$ & $1.18 \pm 0.20^{*}$ \\
0.50 & $1.29 \pm 0.11$ & $1.90 \pm 0.19^{*}$ & $1.49 \pm 0.35$ & $1.27 \pm 0.24$ & $2.03 \pm 0.23^{*}$ \\
1.00 & $1.87 \pm 0.24$ & $4.44 \pm 0.44^{*}$ & $2.61 \pm 0.50^{*}$ & $2.98 \pm 0.26^{*}$ & $3.41 \pm 0.25^{*}$ \\
1.50 & $2.4 \pm 0.33$ & $7.44 \pm 0.69^{*}$ & $3.73 \pm 0.95$ & $5.25 \pm 0.35^{*}$ & $4.52 \pm 0.30^{*}$ \\
\hline
\end{tabular}

*: $\mathrm{p}<0.05$ versus Bennett (Wilcoxon test). 


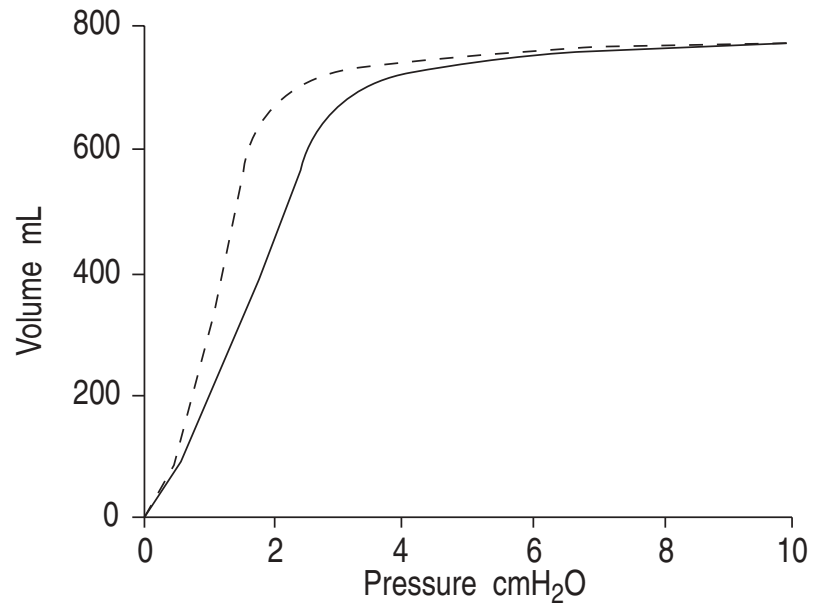

Fig. 3. - Illustration of the pressure volume relationship during expiration in the dynamic condition with the least (Bennett; - - - ) and the most (Peters; _ ) resistive expiratory valve.

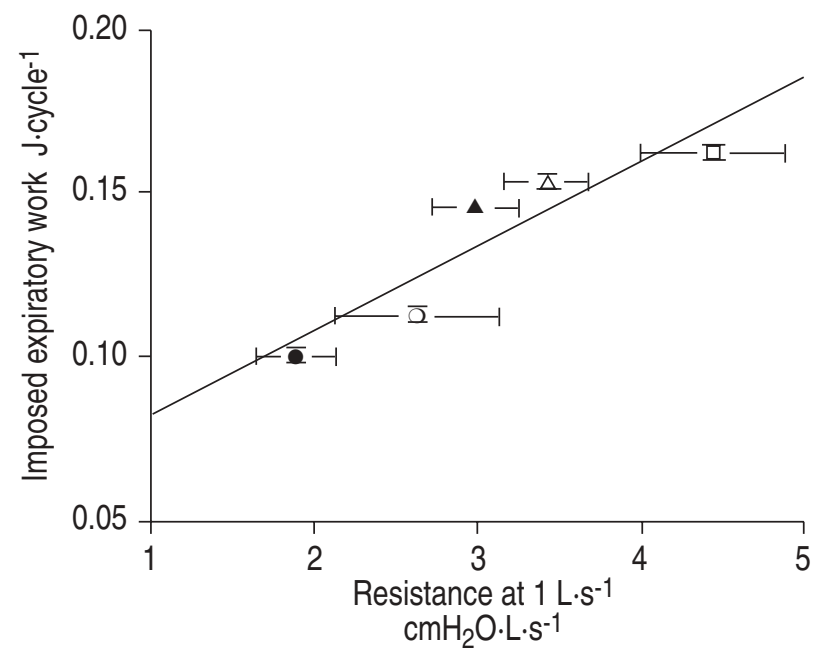

Fig. 4. - Plot of the imposed expiratory work of breathing obtained in the dynamic condition as a function of the expiratory resistance obtained in the quasi-static condition at $1 \mathrm{~L} \cdot \mathrm{s}^{-1}$ for the five expiratory valves tested. A significant correlation was observed $(\mathrm{p}<0.03 ; \mathrm{r}=0.92)$.

๑: Bennett; O: Taema; $\mathbf{\Delta}$ : Sims; ý: Pierre; ๑: Peters.

Table 4. - Mean values ( \pm SD) of breathing pattern, arterial blood gases and oesophageal pressure-time pro-duct with the Bennett and the Peters expiratory valves

\begin{tabular}{lcc}
\hline & Bennett & Peters \\
\hline$V_{\mathrm{T}} \mathrm{mL}$ & $553 \pm 99$ & $557 \pm 93$ \\
$V^{\prime} \mathrm{E} \mathrm{L} \cdot \mathrm{min}^{-1}$ & $13.7 \pm 3.4$ & $13.7 \pm 3.5$ \\
$f_{\mathrm{R}} \mathrm{breaths} \cdot \mathrm{min}^{-1}$ & $25.6 \pm 7.7$ & $25.5 \pm 8.1$ \\
$\mathrm{PEEPi} \mathrm{cmH} \mathrm{O}_{2} \mathrm{O}$ & $2.0 \pm 2.4$ & $2.8 \pm 3.5$ \\
$\mathrm{PTPoes} \mathrm{cmH}{ }_{2} \mathrm{O} \cdot \mathrm{s} \cdot \mathrm{min}^{-1}$ & $194 \pm 90$ & $236 \pm 113^{*}$ \\
$\mathrm{Arterial} \mathrm{pH}$ & $7.38 \pm 0.10$ & $7.38 \pm 0.10$ \\
$P_{\mathrm{a}, \mathrm{O}_{2}} \mathrm{mmHg}$ & $136 \pm 54$ & $137 \pm 63$ \\
$P_{\mathrm{a}, \mathrm{CO}_{2}} \mathrm{mmHg}$ & $42 \pm 11$ & $42 \pm 11$ \\
\hline
\end{tabular}

*: $\mathrm{p}<0.05$ versus Bennett. $V$ T: tidal volume; $V^{\prime} \mathrm{E}$ : minute ventilation; $f \mathrm{R}$ : respiratory frequency; PEEPi: intrinsic positive endexpiratory pressure; PTPoes: oesophageal pressure-time product; $P \mathrm{a}, \mathrm{O}_{2}$ : arterial oxygen tension; $\mathrm{Pa}_{\mathrm{a}} \mathrm{CO}_{2}$ : arterial carbon dioxide tension; $1 \mathrm{mmHg}=0.133 \mathrm{kPa}$.
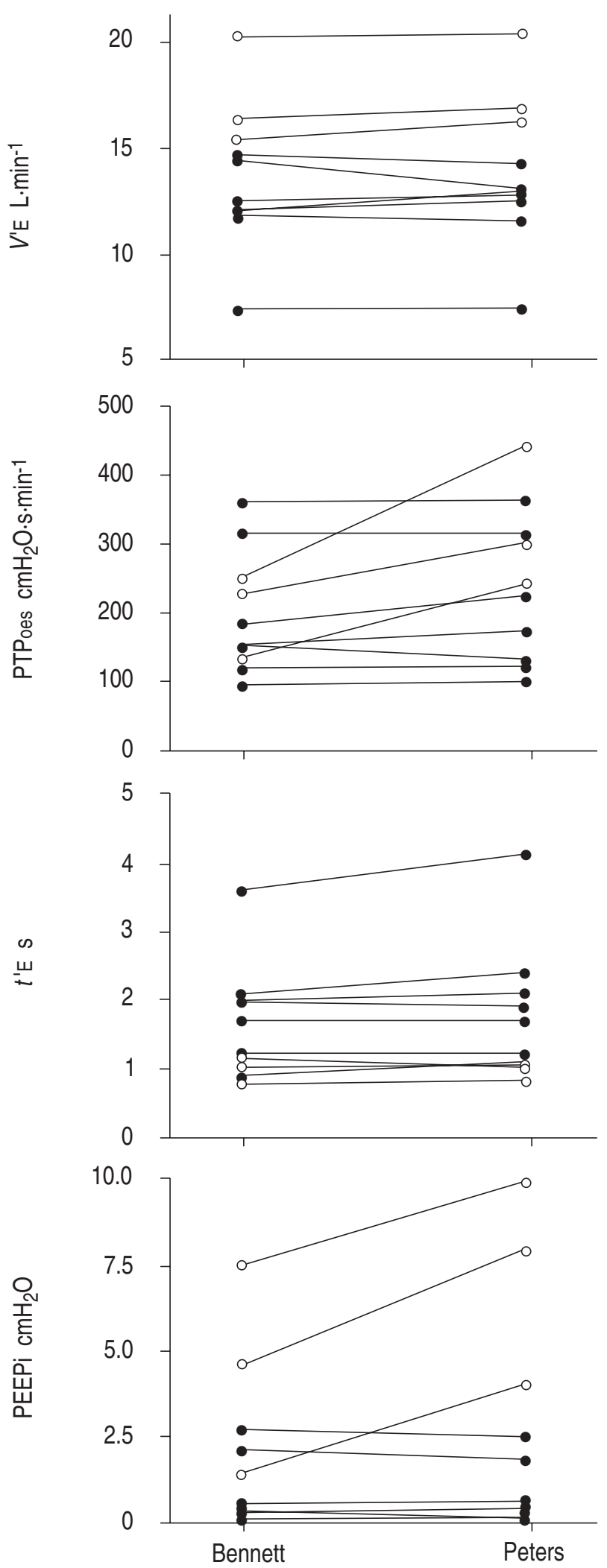

Fig. 5. - Individual values of minute ventilation $\left(V^{\prime} \mathrm{E}\right)$, expiratory time $\left(t^{\prime} \mathrm{E}\right)$, oesophageal pressure-time product (PTPoes) and intrinsic positive end-expiratory pressure (PEEPi) obtained in nine patients with the least (Bennett) and the most (Peters) resistive expiratory valve. Open circles represent the three patients who presented an increase in PEEPi and PTPoes with the Peters expiratory valve. 
a)
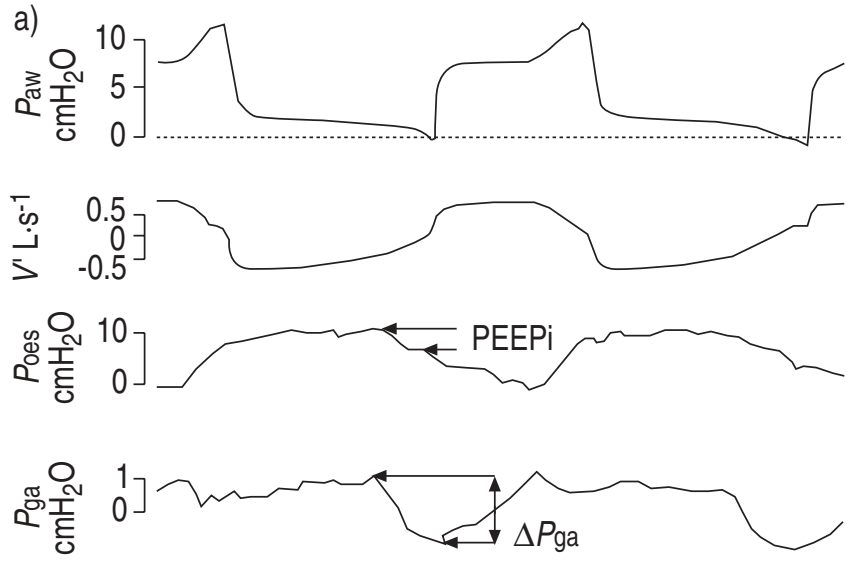

b)
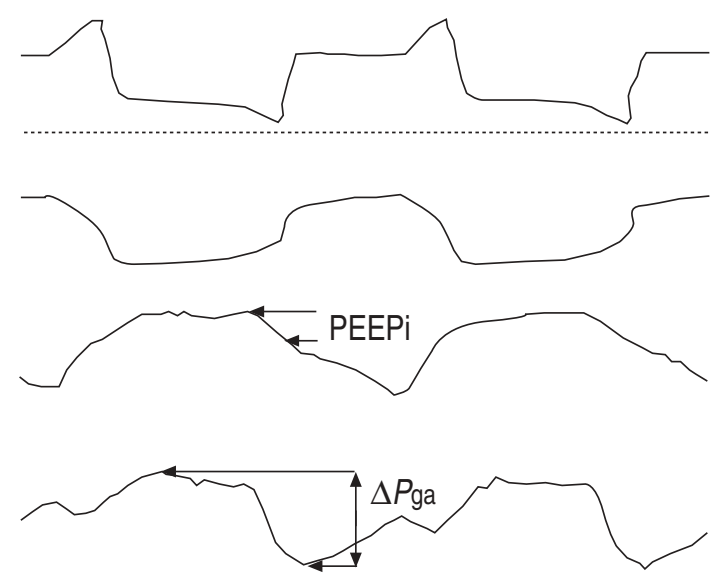

$1 \mathrm{~s}$

Fig. 6. - Representative recordings of airway pressure $\left(P_{\text {aw }}\right)$, flow $\left(V^{\prime}\right)$, oesophageal pressure $\left(P_{\text {oes}}\right)$ and gastric pressure $\left(P_{\text {ga }}\right)$ in patient 7 . Tracings demonstrated increases in $P$ aw during expiration, intrinsic positive end-expiratory pressure (PEEPi), and decline in $P$ ga (ý $P$ ga) with: a) the expiratory Peters valve as compared to b) the expiratory Bennett valve.

valve (fig. 5). In addition, two of these three patients (patients 7 and 10) demonstrated detectable expiratory activity, which increased with the Peters valve, as evidenced by an increase in $\Delta P$ ga from 1.8 to $2.5 \mathrm{cmH}_{2} \mathrm{O}$ (patient 7; fig. 6) and from 3.7 to $4.3 \mathrm{cmH}_{2} \mathrm{O}$ (patient 10). No expiratory activity could be detected on gastric pressure tracings in the other patients.

\section{Discussion}

Resistance through the expiratory limb of the circuit is due primarily to the exhalation valve. Excessive resistance of the expiratory valve can impair exhalation, which can result in PEEPi. Minor fluctuations in PEEPi may have little practical relevance when expiration occurs passively and inflation is driven by the ventilator. However, during assisted ventilation, it is inspiratory flow initiation by the patient that triggers ventilator assistance. Any PEEPi induced by expiratory valve resistance is a supplemental inspiratory threshold load that must be counterbalanced before inspiratory flow can start and initiate ventilator assistance. In addition, the expiratory activity seen in some patients with acute or stable conditions prior to ventilation $[10,11]$ may be increased by expiratory valve resistance [13].

Among available assisted ventilation modalities, PSV has been widely used [1, 14]. More recently, PSV via a nasal mask has been widely advocated as home treatment for chronic respiratory failure [15-17]. This prompted us, in a recent study, [5] to investigate the performances of various home PSV devices. We found several differences between devices, including marked variation in expiratory resistance. After this study was published, several manufacturers suggested that a range of commercially available expiratory valves could be used on the same IPS devices. Therefore, we designed the present study to evaluate the specific performances of several available expiratory valves and the clinical relevance of any differences in these performances.

In an early study by MARIN $e t$ al. [6] of the resistance of various intensive care expiratory circuits, the diaphragm valve, as compared to other designs such as scissor valves, was found to produce a level of resistance of similar magnitude to that of a $5 \mathrm{~mm}$ endotracheal tube. Such a high level of resistance may be clinically important in patients supported by mechanical ventilation during the hyperpnoeic or weaning phase of a respiratory illness. Incidentally, although remarkable technical improvements have been made on ventilators in the last $10 \mathrm{yrs}$, the Peters expiratory valve tested in the present study behaved similarly, in both the quasi-static and dynamic conditions, to the diaphragm valve tested in the study by MARIN et al. [6]. In general, we found marked differences across the commercially-available expiratory valves tested in our study. For example, the resistance at $1 \mathrm{~L} \cdot \mathrm{s}^{-1}$ in the quasi- static analysis was reduced by more than $50 \%$ and the imposed expiratory work in the dynamic analysis by $30 \%$ with the Bennett expiratory valve versus the Peters expiratory valve. We investigated the potential clinical rele-vance of these differences. For the reasons explained ab- ove, we expected to find higher PEEPi, and consequently PTPoes, with the most resistive compared to the least resistive valve. However, in intubated patients being weaned from mechanical ventilation we were unable to demonstrate significant differences between these two valves re-garding blood gas parameters, respiratory parameters or PEEPi. We did observe a significant increase in PTPoes with the Peters valve despite the absence of any significant change in PEEPi.

The alveolar expiratory pressure-time curve has been described mathematically by a first-order exponential function, which, at the end of expiration, equals PEEPi and can be expressed as $[18,19]$ :

$$
\mathrm{PEEPi}=(V \mathrm{~T} / C) \mathrm{e}^{-\mathrm{t}} \mathrm{E} / \mathrm{RC}
$$

where $\mathrm{R}$ is resistance, $\mathrm{C}$ is compliance and $\mathrm{RC}$ is the time constant of the respiratory system. $R$ includes the resistance of the expiratory circuit, so that an increase in expiratory valve resistance results in an increase in PEEPi through the increase in time constant. 
TuXeN and Lane [20] validated this mathematical mo-del in mechanically ventilated patients with severe air- flow obstruction and demonstrated unequivocally that the risk of dynamic hyperventilation was greater when the volume delivered by the ventilator $(V \mathrm{~T})$ was increased and $t \mathrm{E}$ reduced. Consistent with these findings, our analysis of individual responses showed that the three patients with the highest minute ventilation (above $15 \mathrm{~L} \cdot \mathrm{min}^{-1}$ ) and the shortest expiratory time (fig. 5) exhibited substantial increases in PEEPi and, consequently, in PTPoes. In addition, the significant increase in PTPoes observed with the Peters valve was mainly due to these three patients. Furthermore, for two of these three patients, part of the increase in PEEPi with the Peters expiratory valve was explained by an increase in expiratory activity evidenced by an increase in $\Delta P$ ga (fig. 6 ).

We conclude that important differences in resistance exist between commercially-available expiratory valves for home ventilator devices. In addition, these differences may influence both inspiratory and expiratory efforts in patients with a marked ventilatory demand and/or a short expiratory time. For these reasons, as previously recommended for intensive care ventilators [6], it is imperative that greater attention be devoted to the design and selection of expiratory components of ventilator circuits.

Acknowledgements: The authors are grateful to A. Quintel for skillful technical assistance.

\section{References}

1. Hill N. Noninvasive ventilation. Does it work, for whom, and how? Am Rev Respir Dis 1993; 147: 1050-1055.

2. Pennock B, Kaplan P, Carlin B, Sabangan J, Magovern J. Pressure support ventilation with a simplified ventilatory support system administered with a nasal mask in patients with respiratory failure. Chest 1991; 100: 13711376.

3. Strumpf D, Carlisle C, Millman R, Smith K, Hill N. An evaluation of the Respironics BiPAP Bi-Level CPAP device for delivery of assisted ventilation. Respir Care 1990; 35: 415-422.

4. Lofaso F, Brochard L, Touchard D, Hang T, Harf A. Isabey D. Evaluation of carbon dioxide rebreathing during pressure support ventilation with BiPAP devices. Chest 1995; 108: 772-778.

5. Lofaso F, Brochard L, Hang T, Lorino H, Harf A, Isabey D. Home versus intensive-care pressure support devices, experimental and clinical comparison. Am J Respir Crit Care Med 1996; 153: 1591-1599.
6. Marini J, Culver B, Kirk W. Flow resistance of exhalation valves and positive end-expiratory pressure devices used in mechanical ventilation. Am Rev Respir Dis 1985; 131: 850-854.

7. Kayaleh R, Wilson A. Mechanisms of expiratory valves resistance. Am Rev Respir Dis 1988; 137: 1390-1394.

8. Banner M, Lampotang S. Expiratory pressure valve. In: Branson R, Hess D, Chatburn R, eds. Respiratory Care Equipment. Philadelphia, Lippincott Company, 1995; pp. 479-488.

9. Baydur A, Behrakis PK, Zin WA, Jaeger M, Milic-Emili J. A simple method for assessing the validity of the esophageal balloon technique. Am Rev Respir Dis 1982; 126: 788-791.

10. Ninane V, Yernault JC, Troyer AD. Intrinsic PEEP in patients with chronic obstructive pulmonary disease. Am Rev Respir Dis 1993; 148: 1037-1042.

11. Lessard MR, Lofaso F, Brochard L. Expiratory muscle activity increases intrinsic positive end-expiratory pressure independently of dynamic hyperinflation in mechanically ventilated patients. Am J Respir Crit Care Med 1995; 151: 562-569.

12. Yan S, Kayser B, Tobiasz M, Sliwinski P. Comparison of static and dynamic intrinsic positive end-expiratory pressure using the Campbell diagram. Am J Respir Crit Care Med 1996; 154: 938-944.

13. Campbell E. The effects of increased resistance to expiration on the respiratory behavior of the abdominal muscles and intra-abdominal pressure. J Physiol 1957; 136: 556563.

14. Brochard L. Non-invasive ventilation: practical issues. Intens Care Med 1993; 19: 431-432.

15. Nava S, Ambrosino N, Rubini F, et al. Effect of nasal pressure support ventilation and external PEEP on diaphragmatic activity in patients with severe stable COPD. Chest 1993; 103: 145-150.

16. Carrey Z, Gottfried S, Levy R. Ventilatory muscle support in respiratory failure with nasal positive pressure ventilation. Chest 1990; 97: 150-158.

17. Strumpf D, Millman R, Carlisle C, et al. Nocturnal positive pressure ventilation via nasal mask in patients with severe chronic obstructive pulmonary disease. Am Rev Respir Dis 1991; 144: 1234-1239.

18. Brody A. Mechanical compliance and resistance of the lung-thorax calculated from the flow recorded during passive expiration. Am J Physiol 1954; 178: 189-196.

19. Ligas J, Moslehi F, Epstein M. Occult positive end-expiratory pressure with different types of mechanical ventilators. J Crit Care 1990; 5: 95-100.

20. Tuxen D, Lane S. The effect of ventilatory pattern on hyperinflation, airway pressure and circulation in mechanical ventilation of patients with severe air-flow obstruction. Am Rev Respir Dis 1987; 136: 872-879. 